Article

\title{
Impact of circ-0000221 in the Pathogenesis of Hepatocellular via Modulation of miR-661-PTPN11 mRNA Axis
}

\author{
Marwa Matboli ${ }^{1, *,+}$ D, Mohmed Kamal Hassan $2,3,+$, Mahmoud A. Ali ${ }^{4}$, Mohamed Tarek Mansour ${ }^{4}$, \\ Waheba Elsayed ${ }^{2}$ D, Reham Atteya ${ }^{2}$, Hebatallah Said Aly ${ }^{1}$, Mahmoud El Meteini ${ }^{5}$, Hesham Elghazaly ${ }^{6}$, \\ Sherif El-Khamisy $7,8,+(\mathbb{D}$ and Sara H. A. Agwa $9, *(\mathbb{D})$
}

Citation: Matboli, M.; Hassan, M.K.; Ali, M.A.; Mansour, M.T.; Elsayed, W.; Atteya, R.; Aly, H.S.; Meteini, M.E.; Elghazaly, H.; El-Khamisy, S.; et al. Impact of circ-0000221 in the Pathogenesis of Hepatocellular via Modulation of miR-661-PTPN11 mRNA Axis. Pharmaceutics 2022, 14, 138. https://doi.org/10.3390/ pharmaceutics14010138

Academic Editors: Dan Peer, Philippe Barthélémy and Tina Kauss

Received: 24 November 2021

Accepted: 5 January 2022

Published: 6 January 2022

Publisher's Note: MDPI stays neutral with regard to jurisdictional claims in published maps and institutional affiliations.

Copyright: (C) 2022 by the authors. Licensee MDPI, Basel, Switzerland. This article is an open access article distributed under the terms and conditions of the Creative Commons Attribution (CC BY) license (https:// creativecommons.org/licenses/by/ $4.0 /)$.
1 Medical Biochemistry and Molecular Biology Department, Faculty of Medicine, Ain Shams University, Abbassia, Cairo 11381, Egypt; hebatallahsaid@med.asu.edu.eg

2 Center for Genomics, Helmy Institute for Medical Sciences, Zewail City for Science and Technology, Giza 12578, Egypt; mfarah@zewailcity.edu.eg (M.K.H.); p-walsayed@zewailcity.edu.eg (W.E.); p-rattaeya@zewailcity.edu.eg (R.A.)

3 Biotechnology Program, Biology Division, Zoology Department, Faculty of Science, Port Said University, Port Said 42526, Egypt

4 Department of Biomedical Research, Armed Forces College of Medicine (AFCM), Cairo 11774, Egypt; mahmoudali@gmail.com (M.A.A.); habibaabdelnaser70@gmail.com or mohammadtarek459@gmail.com (M.T.M.)

5 Department of General Surgery, The School of Medicine, University of Ain Shams, Abbassia, Cairo 11382, Egypt; mahmoud_elmeteini@med.asu.edu.eg

6 Oncology Department, Faculty of Medicine, Medical Ain Shams Research Institute (MASRI), Ain Shams University, Cairo 11382, Egypt; heshamelghazaly@med.asu.edu.eg

7 The Healthy Lifespan Institute, The Institute of Neuroscience, Department of Molecular Biology and Biotechnology, University of Sheffield, Sheffield S10 2TN, UK; s.el-khamisy@sheffield.ac.uk

8 The Institute of Cancer Therapeutics, West Yorkshire BD7 1DP, UK

9 Clinical pathology and Molecular Genomics Unit, Faculty of Medicine, Medical Ain Shams Research Institute (MASRI), Ain Shams University, Cairo 11382, Egypt

* Correspondence: DrMarwa_Matboly@med.asu.edu.eg (M.M.); sara.h.agwa@med.asu.edu.eg (S.H.A.A.)

+ These authors contributed equally to this work.

\begin{abstract}
Hepatocellular carcinoma (HCC) is a leading cause of cancer-related death in Egypt. A deep understanding of the molecular events occurring in HCC can facilitate the development of novel diagnostic and/or therapeutic approaches. In the present study, we describe a novel axis of hsa-circ-0000221-miR-661-PTPN11 mRNA proposed by in silico and in vitro analysis and its role in HCC pathogenesis. We observe a reduction in the expression levels of hsa-circ-0000221 and PTPN11 mRNA in HCC patients' sera tested compared with control subjects. The reduction occurs with a concomitant increase in the expression of miR-661. Furthermore, the introduction of exogenous hsa-circ-0000221 into Hep-G2 or SNU449 cell lines results in detectable decrease in cellular viability and an increase in apoptotic manifestations that is associated with G1 accumulation and CCDN1 overexpression. Altogether, these findings indicate the tumor-suppressive role of hsa-circ-0000221 in HCC, which acts through miR-661 inhibition, along with a subsequent PTPN11 mRNA increase, where PTPN11 is known to inhibit cell proliferation in many forms of cancer. Our study encourages further investigation of the role of circRNAs in cancer and their potential use as molecular biomarkers.
\end{abstract}

Keywords: hepatocellular carcinoma; hsa-circ-0000221; miR-661; PTPN11

\section{Introduction}

Hepatocellular carcinoma (HCC) is the most common type of liver cancer and one of the major causes of cancer-related death worldwide [1]). Early diagnosis of HCC is possible, and radical surgeries are a common treatment modality with mostly favorable prognostic outcomes [2]. However, many patients with HCC are missed with the current diagnostic standards and, therefore, lose the operation opportunity. To improve the therapeutic 
outcome and prognosis of HCC patients, it is imperative to search for more efficient biomarkers to increase the early diagnosis rate of HCC. Many HCC patients respond poorly to sorafenib (the first-line chemotherapeutic therapy for advanced HCC) and develop drug resistance after several months of treatment. Chemotherapeutic resistance in HCC involves different mechanisms, e.g., epithelial-mesenchymal transition, cancer stem cells, autophagy, and epigenetic regulation [3]. Several signaling pathways are enrolled in chemotherapeutic resistance in HCC such as TNF $\alpha / \mathrm{NF}-\kappa \mathrm{B}, \mathrm{Wnt} / \beta$-catenin, TGF $\beta$, Ras/MEK/ERK, and JAK/STAT pathways [4].

Circular RNAs (circRNAs) are a class of noncoding RNAs (ncRNAs) characterized by their covalently closed structure formed by the end-to-end joining of RNA transcripts known as "back splicing" [5] CircRNAs display high levels of stability compared to their ncRNA counterparts, are highly represented in the eukaryotic transcriptome, and often show tissue-/developmental stage-specific expression [6]. They are even present at higher concentrations than messenger RNAs (mRNAs) in the cytoplasm of certain cells [7]. CircRNAs can inhibit the binding of miRNAs to mRNAs through "sponging", thus regulating the expression of their downstream target genes. circRNAs may act as competing endogenous RNA (ceRNA) via modulating miRNA expression, leading to NF- $\kappa$ B activation that may result in cancer progression, as well as mediate chemo resistance [8].

CircRNAs are strongly associated with tumors [9] and have previously been shown to play a role in the development and progression of HCC [10]. For example, circRNA-7 has an inhibitory effect on miR-7 via sponging. miR-7 is a tumor-suppressor miRNA demonstrated through several mechanistic studies to be often expressed in relatively low levels in various tumor tissues and is negatively correlated with the growth, invasion, and colony formation of these tumors through regulating different target molecules [11]. miR-7 has also been found to arrest cell cycles at the G0/G1 phase and inhibit the spread and metastasis of HCC through downregulating three target molecules (PIK3CD, mTOR, p70S6K) belonging to the PIK3CD/Akt signaling pathway [12]. circRNA-SORE (a circular RNA upregulated in sorafenib-resistant HCC cells) plays a crucial role in the maintenance and spread of sorafenib resistance [4].

In the current study, we used in silico data to uncover the hsa-circ-0000221-miR-661PTPN11 mRNA axis, relevant to HCC with significant differential expression, followed by validation in HCC cells and in clinical samples representing a small pilot study to examine their expression levels in serum samples.

\section{Materials \& Methods}

\subsection{In Silico Analysis and Prediction}

Circ2Traits (Available at http:/ / gyanxet-beta.com/circdb/, Accessed on 23 November 2019) [13] and CircNet (Available at http:/ / circnet.mbc.nctu.edu.tw / , Accessed on 23 November 2019) [14] bioinformatics databases were used for retrieval of HCC-specific circRNA. Afterward, HCC-relevant miRNA targets of circular RNA hsa_circ_0000221, as well as their binding sites on the circular RNA, were predicted using the CircInteractome tool (Available at http:/ / circinteractome.nia.nih.gov/, Accessed on 23 November 2019) [15], The mRNA targets of hsa-mir-661 were predicted using TargetScan (Available at http://www. targetscan.org/) [16] and miRWalk (Available at zmf.umm.uni-heidelberg.de/apps/zmf / mirwalk2/, Accessed on 23 November 2019) [17] databases. The network of circRNAmiRNA-mRNA was constructed using Cytoscape software (Version 3.5.1) (Available at http: / / www.cytoscape.org/, Accessed on 23 November 2019) [18]. Lastly, the protein-protein interactions of PTPN11, as well as their pathway enrichment, were studied through the STRING database (Available at http: / / string-db.org/, Accessed on 23 November 2019) [19].

To gain insights into the role of $h$ sa-circ-0000221 in HCC, the predicted miRNA targets of the circular RNA were subjected to pathway enrichment analysis using the miRPath tool (Available at http:/ / snf-515788.vm.okeanos.grnet.gr/, Accessed on 23 November 2019) [20]. Additionally, the predicted target mRNAs of hsa-mir-661 were subjected to gene ontology prediction through GOSlim on the Web Gestalt database (Available at http: / / www. 
webgestalt.org, Accessed on 23 November 2019) [21]. Subsequently, the Enrich tool (Available at http://amp.pharm.mssm.edu/Enrichr/, Accessed on 23 November 2019) was used to predict the significant pathways where hsa-mir-661 targets could be enriched. To predict the functional implications of PTPN11 regulation in HCC and its targeting by miRNAs, the miRWalk database [17] was used. Additionally, the STRING database [22] was used to analyze the protein-protein interactions of PTPN11 and investigate the enriched KEGG pathways.

\subsection{Antibodies and Reagents}

The following antibodies were used for Western blotting: mouse anti-human BAX $\mathrm{mAb}$, cyclin D1 mAb, cyclin B1 mAb, (BD Bioscience; Erembodegem, Belgium), procaspase$3 \mathrm{mAb}$, active caspase-3 mAb, PARP mAb (Santa Cruze, CA, USA), and rabbit anti-human GAPDH pAb (Abcam, Cambridge, UK). All were used at a dilution of 1:200, except GAPDH which was used at a dilution of 1:1000. As for immunoblotting detection, either anti-mouse or anti-rabbit secondary horseradish peroxidase-conjugated antibodies (Dako, Glostrup, Denmark) were used and diluted at 1:1000.

\subsection{Cell Lines}

The human hepatocellular carcinoma cell lines used in this study, HepG2 and SNU449, were obtained from ATCC. HepG-2 cells were maintained in Dulbecco's modified Eagle's medium (DMEM, Gibco-BRL, Gaithersburg, MD, USA) while SNU449 cells were maintained in RPM1640 medium (Sigma, St. Louis, MO, USA). The media of both cells contained $10 \%$ heat-inactivated fetal bovine serum (FBS, Gibco-BRL), $1 \%$ L-glutamine, and $1 \%$ penicillin/streptomycin (Gibco-BRL), and they were cultured at $37^{\circ} \mathrm{C}$ in a $5 \% \mathrm{CO}_{2}$ atmosphere. HepG2 and SNU449 cells were used from passage number 40 to 51 for the experiments in this study. For transfection assays, cells were seeded to be around $60-70 \%$ confluency on the day of transfection.

\subsection{Human Samples}

This study was approved by the institutional review committee board of Ethics, Ain Shams University, Faculty of Medicine, Egypt, under the Code of Ethics of the World Medical Association (Helsinki Declaration) with the approval number FMASU MD 32/2016. Informed written consent was obtained from every participant. Participants were recruited from the clinic of Tropical Medicine Department, Ain Shams University Hospital in the period from January to April 2016. All patients who had received radiation, chemotherapy or surgical intervention were excluded from the study. Demographic data of the population of patients in this study are summarized in Table 1 . Serum samples from 25 histologically confirmed HCC patients, 15 hepatitis $\mathrm{C}$ virus (HCV) patients, and 10 healthy normal participants were used for total RNA isolation using miRNeasy Mini Spin Columns (Qiagen, Hilden, Germany).

Table 1. Study population demographic and clinical characteristics $(N=50)$.

\begin{tabular}{|c|c|c|c|c|c|}
\hline & $\begin{array}{l}\text { Malignant } \\
\quad(n=25)\end{array}$ & $\begin{array}{c}\text { CHC } \\
(n=15)\end{array}$ & $\begin{array}{l}\text { Normal } \\
(n=10)\end{array}$ & $p$ & $\begin{array}{l}\chi^{2(a)} \\
F^{(b)}\end{array}$ \\
\hline $\begin{array}{c}\text { Age } \\
\geq 57 \text { years }(n=29) \\
<57 \text { years }(n=21)\end{array}$ & $\begin{array}{l}14(56 \%) \\
11(44 \%)\end{array}$ & $\begin{array}{c}10(66.7 \%) \\
5(33.3 \%)\end{array}$ & $\begin{array}{l}5(50 \%) \\
5(50 \%)\end{array}$ & 0.68 & $\chi^{2(a)}=0.76$ \\
\hline $\begin{array}{c}\text { Sex: } \\
\text { Male }(n=27) \\
\text { Female }(n=23)\end{array}$ & $\begin{array}{c}16(66 \%) \\
9(34 \%)\end{array}$ & $\begin{array}{c}4(26.7 \%) \\
11(73.3 \%)\end{array}$ & $\begin{array}{l}7(70 \%) \\
3(30 \%)\end{array}$ & 0.051 & $x^{2(a)}=6.5$ \\
\hline $\begin{array}{c}\text { Smoking: } \\
\text { Smoker }(n=17) \\
\text { Nonsmoker }(n=33)\end{array}$ & $\begin{array}{c}9(36 \%) \\
16(64 \%)\end{array}$ & $\begin{array}{l}6(40 \%) \\
9(60 \%)\end{array}$ & $\begin{array}{l}2(20 \%) \\
8(80 \%)\end{array}$ & 0.56 & $\chi^{2(a)}=0.125$ \\
\hline
\end{tabular}


Table 1. Cont.

\begin{tabular}{|c|c|c|c|c|c|}
\hline & $\begin{array}{c}\text { Malignant } \\
\quad(n=25)\end{array}$ & $\begin{array}{c}\text { CHC } \\
(n=15)\end{array}$ & $\begin{array}{l}\text { Normal } \\
(n=10)\end{array}$ & $p$ & $\begin{array}{l}\chi^{2(a)} \\
F^{(b)}\end{array}$ \\
\hline $\begin{array}{l}\text { HCV antibodies: } \\
\text { Positive }(n=35) \\
\text { Negative }(n=15)\end{array}$ & $\begin{array}{c}21(84 \%) \\
4(16 \%)\end{array}$ & $\begin{array}{c}14(93.3 \%) \\
1(6.7 \%)\end{array}$ & $\begin{array}{c}0(0 \%) \\
10(100 \%)\end{array}$ & $0.000^{* *}$ & $\chi^{2(a)}=17.5$ \\
\hline $\begin{array}{c}\text { HBV sAg: } \\
\text { Positive }(n=1) \\
\text { Negative }(n=49)\end{array}$ & $\begin{array}{c}1(4 \%) \\
24(96 \%)\end{array}$ & $\begin{array}{c}0(0 \%) \\
15(100 \%)\end{array}$ & $\begin{array}{c}0(0 \%) \\
10(100 \%)\end{array}$ & 0.061 & $\chi^{2(a)}=1.596$ \\
\hline $\begin{array}{c}\text { Cirrhosis: } \\
\text { Cirrhotic }(n=29) \\
\text { Noncirrhotic }(n=21)\end{array}$ & $\begin{array}{c}21(84 \%) \\
4(16 \%)\end{array}$ & $\begin{array}{l}8(53.3 \%) \\
7(46.7 \%)\end{array}$ & $\begin{array}{c}0(0 \%) \\
10(100 \%)\end{array}$ & $0.000 * *$ & $\chi^{2(a)}=13.1$ \\
\hline AST & $75.6 \pm 43.66$ & $68.4 \pm 18.4546$ & $38.06 \pm 18.1$ & $0.000 * *$ & $F^{(b)}=19.7$ \\
\hline ALT & $54.1 \pm 46.2$ & $39.1 \pm 17.27$ & $29.3 \pm 11.43$ & $0.000 * *$ & $\mathrm{~F}^{(\mathrm{b})}=17.2$ \\
\hline Albumin & $2.74 \pm 0.31$ & $3.31 \pm 0.22$ & $3.6 \pm 0.5$ & $0.000 * *$ & $\mathrm{~F}^{(\mathrm{b})}=45.3$ \\
\hline Total Bilirubin & $4.9 \pm 0.57$ & $3.8 \pm 2.76$ & $1.38 \pm 1.7627$ & $0.000^{* *}$ & $\mathrm{~F}^{(\mathrm{b})}=24.5$ \\
\hline Direct Bilirubin & $2.89 \pm 0.55$ & $2.6 \pm 3.4$ & $0.73 \pm 1.2$ & $0.000 * *$ & $F^{(b)}=11.05$ \\
\hline INR & $1.4 \pm 0.3$ & $1.3 \pm 0.095$ & $1.14 \pm 0.15$ & $0.000^{* *}$ & $\mathrm{~F}^{(\mathrm{b})}=57.3$ \\
\hline$\alpha$-feto-protein & $3193.90 \pm 485.7$ & $525.52 \pm 122.3$ & $165.66 \pm 2.2$ & $0.000 * *$ & $\mathrm{~F}^{(\mathrm{b})}=11.7$ \\
\hline Child score & & \multirow{7}{*}{-} & \multirow{7}{*}{-} & \multirow{7}{*}{-} & \multirow{7}{*}{-} \\
\hline A5 & $4(16 \%)$ & & & & \\
\hline A6 & $3(12 \%)$ & & & & \\
\hline B6 & $6(24 \%)$ & & & & \\
\hline B7 & $1(4 \%)$ & & & & \\
\hline B8 & $5(20 \%)$ & & & & \\
\hline $\mathrm{C} 10$ & $6(24 \%)$ & & & & \\
\hline
\end{tabular}

Mean size of the tumor

$\begin{array}{ll}\geq 3 \mathrm{~cm} & 18(72 \%) \\ <3 \mathrm{~cm} & 7(28 \%)\end{array}$

BCLC stage

A $23(92 \%)$

D $2(8 \%)$

${ }^{\mathrm{a}}$ Chi-square test; ${ }^{\mathrm{b}}$ one-way ANOVA test; ${ }^{* *}$ highly significant correlation was detected between investigated groups at $p<0.01$. HCV: hepatitis $\mathrm{C}$ virus, $\mathrm{CHC}$ : chronic $\mathrm{HCV}$ infection, $\mathrm{HBV}$ sAg: hepatitis $\mathrm{B}$ virus surface antigen, AST: aspartate transaminase, ALT: alanine transaminase, INR: international normalized ratio, BCLC: Barcelona clinic liver cancer.

\subsection{QRT-PCR for circRNA-miRNA-mRNA Genetic Network in Human Serum Samples}

The RT2 miRNA First-Strand Kit (Qiagen, Valencia, CA, USA) using miScript HiSpec buffer was used to prepare cDNA from $1 \mu \mathrm{g}$ of RNA. Real-time PCR was performed on the Step One Plus ${ }^{\mathrm{TM}}$ System (Applied Biosystems Inc., Foster, CA, USA). All reactions were performed in triplicate.

The hsa-circ-000520 and PTPN mRNA (NM_002834) expression in HCC cell lines was assessed using QuantiTect SYBR Green PCR Kit (Qiagen, Valencia, CA, USA) and genespecific primers (Circular RNA specific Quantict Primer and Hs_PTPN11_1_SG Quantict Primer), on a Step One Plus ${ }^{\text {TM }}$ System (Applied Biosystems Inc., Foster, CA, USA). Beta-actin was used as a housekeeping gene. Divergent primers for hsa-circ-000520 were designed by the Circinteractome database (Available at http:/ / circinteractome.nia.nih.gov/, Accessed 
on 23 November 2019) and synthesized by Qiagen (Hilden, Germany) (forward primer: AGCGCACCTTGTCGATGTAG; reverse primer: AGAATAAGATCCTGCTGGCCG).

miR-661 expression in HCC cell lines was assessed by mixing the total cDNAs with a miRNA-specific forward primer (miScript Primer Assay) (accession: MIMAT0003324) and miScript SYBR Green PCR Kit (Qiagen/SABiosciences Corporation, Frederick, MD, USA) according to the manufacturer's protocol. RNU-6 was used as an internal control.

The PCR program for SYBR green-based qPCR was as follows: denaturation at $95^{\circ} \mathrm{C}$ for $15 \mathrm{~min}$, followed by 40 cycles of denaturation for $10 \mathrm{~s}$ at $94{ }^{\circ} \mathrm{C}$, then annealing for $30 \mathrm{~s}$ at $55{ }^{\circ} \mathrm{C}$, and a final extension for $34 \mathrm{~s}$ at $70{ }^{\circ} \mathrm{C}$. Each reaction was done in duplicate. Relative quantification of gene expression was calculated using the $2^{-\Delta \Delta \mathrm{Ct}}$ method [23]. The cycle threshold $(\mathrm{Ct})$ value of each sample was calculated using Step One Plus ${ }^{\mathrm{TM}}$ software v2.2.2 (Applied Biosystems). Any Ct value above 36 was considered negative. Amplification plots and $\mathrm{T}_{\mathrm{m}}$ values were checked to ensure the specificities of the amplicons.

\subsection{Viability Assay}

Cell viability was assayed utilizing a cell counting kit (CCK-8; Dojindo, Kumamoto, Japan). A 96-well plate containing precultured cells (3000 cells/well) was subjected to medium replacement by the WST-8 reagent (2-(2-methoxy-4-nitrophenyl)-3-(4-nitrophenyl)5-2,4-disulphonyl)-2H-tetrazolium monosodium salt) (which, when reduced, turns to orange formazan) at the indicated timepoints. Both the developed color and the absorbance were measured at $450 \mathrm{~nm}$ using a microplate reader (FLUOstar Omega, BMG labtech, Ortenburg, Germany), with the amount of formazan being directly proportional to the number of living cells.

\subsection{Clonogenic Assay}

SNU449 and HepG2 cells were cultured in the proper medium (at 50-60\% confluence). The following day, cells were transfected with either the hsa-circ-0000221 expressing vector or the mock. One day after transfection, cells were trypsinized and re-cultured at 400 cells $/ 3 \mathrm{~cm}$ dishes. Two weeks later, colonies were fixed by $70 \%$ methanol and stained with Giemsa, and pictures were taken for at least three pairs of dishes from each different experiment. Colonies were counted and the survival fraction was calculated relative to the vector control.

\subsection{Plasmid Construction and Transfection}

We generated $h s a$-circ-0000221 cDNA using serum samples. Then, $2 \mu \mathrm{L}$ of RNA was reverse-transcribed by QIAGEN OneStep RT-PCR Kit (Qiagen, Valencia, CA, USA). The divergent primers for $h s a$-circ-000520 were used for PCR and generated a PCR product with a size consistent with the target fragment and that published on CircBase. The hsa-circ-0000221 fragment was cloned into T/A cloning vector using T/A cloning kit (Invitrogen, Carlsbad, CA, USA). and then subcloned into pcDNA ${ }^{\mathrm{TM}} 3.1(+)$ vector (Invitrogen, Carlsbad, CA, USA) using T4 DNA. The target fragment was sequenced to determine its full length and to confirm the back-splice junction of hsa-circ-0000221: 5'-AGGTCCCCCAGGCGCGACTTGCCTTGGCCCTTGAGCTGCTCGAGCTCGGCCAGC AGGATCTTATTCTGCTGCTCCAGGAAGCGCACCTTGTCGATGTAGTTGGCGAAGC GGTCATTCAGCTCCTGCAGCTCCACCTTCTCGTTG-3'.

The construct was introduced into cells using Lipofectamine ${ }^{\mathrm{TM}} 2000$ reagent (Invitrogen, Carlsbad, CA, USA) according to the manufacturer's instructions. Then, 1 or 2 days after transfection, at least two million HCC cells were used for isolation of total RNA including miRNAs followed by qRT-PCR to detect the expression of the circRNA-associated ceRNA network (as previously described). For co-transfection, the same plasmid was used together with GFP expressing vector at a ratio of 3:1 (circRNA:GFP) 


\subsection{Flow Cytometry Analysis}

After transfection with the target plasmid or mock, phosphate-buffered saline (PBS) was used to wash the trypsinized cells twice, followed by cell-cycle phase analysis. This was done by fixing the cells overnight at $4{ }^{\circ} \mathrm{C}$ in $70 \%$ ethanol. Cells were washed with $\mathrm{Ca}^{2+} / \mathrm{Mg}^{2+}$-free Dulbecco's PBS and treated with $1 \mathrm{mg} / \mathrm{mL}$ RNase (Type I-A; Sigma, St. Louis, MO, USA). Treated cells were then stained using $10 \mu \mathrm{g} / \mathrm{mL}$ propidium iodide (PI; Sigma) for $20 \mathrm{~min}$; then, the cells were filtered and kept on ice until measurement. Cells were obtained using the FACS calibrator using nontreated stained cells. In this study, we quantified and took into consideration cell fractions with a DNA content lower than G0/G1, the sub-G0/G1peak.

\subsection{Annexin V Staining}

Two days after transfection with the target plasmid, cells were harvested and washed with PBS. Then, cells were stained directly with PI at a final concentration of $10 \mu \mathrm{g} / \mathrm{mL}$ and $2 \%$ annexin V Flous (BioRad, Hercules, CA, USA) in incubation buffer (10 mM HEPES/ NaOH, pH 7.4, $140 \mathrm{mM} \mathrm{NaCl}, 5 \mathrm{mM} \mathrm{CaCl}_{2}$ ) for $10 \mathrm{~min}$. Cells were acquired using the FACS calibrator using nontreated stained cells as control. We then quantified cells stained with annexin V (early and middle apoptotic) and those stained with PI (late death). FLowJo software was used to analyze Apoptotic cells.

\subsection{Western Blotting}

RIPA buffer (10 mM Tris (pH 7.4), $150 \mathrm{mM} \mathrm{NaCl}, 1 \%$ Triton X-100, $1 \%$ Na deoxycholate, and $5 \mathrm{mM}$ EDTA) supplemented with a protease inhibitor cocktail (Sigma) was used to obtain cell lysates by resuspending the cells in this mixture. A BCA kit (Pierce, Thermo Fisher Scientific, Waltham, MA, USA) was used to determine protein concentration in the obtained lysates, and then SDS-PAGE was performed. In brief, equal protein concentrations were heated $\left(100^{\circ} \mathrm{C}\right)$ for $3 \mathrm{~min}$ with sodium dodecyl sulfate (SDS) sample buffer $(25 \mathrm{~mL}$ glycerol, $31.2 \mathrm{~mL}$ Tris buffer, $7.5 \mathrm{~mL}$ SDS, a dash of bromophenol blue/100 mL) and run on $10 \%$ SDS polyacrylamide gel electrophoresis (SDS-PAGE). Migrated proteins were then blotted onto PVDF membranes (Immobolin P, Watford, UK). Blocking was performed by incubating the membranes in a blocking solution ( $5 \%$ nonfat milk in PBS) for $1 \mathrm{~h}$. Membranes were incubated with primary antibody (anti-human CLU mAb at dilution of 1:1000) overnight. The membranes were then washed three times for $10 \mathrm{~min}$ in TBS (0.1\% Tween-20 in PBS) followed by incubation for $1 \mathrm{~h}$ at room temperature with horseradish peroxidase-linked IgG (1:2000 dilution in T-TBS), followed by another three washes (10 min each) with TTBS. ECL reagent (Amersham, CA, USA) was used to develop the signals on the membranes which were then imaged by Chemidoc MP imaging system (BioRad; Hercules, CA, USA)

\subsection{DAPI Staining}

Two days after the co-transfection of SNU449 cells with the circRNA-expressing vector and GFP-expressing vector, cells were fixed with $4 \%$ paraformaldehyde and permeabilized with Triton X (1\%) for $4 \mathrm{~min}$. The cells were then washed three times with PBS and stained with DAPI (300 $\mathrm{nM})$ for $10 \mathrm{~min}$. Imaging was performed by an Olympus fluorescence microscope.

\subsection{Statistical Analysis}

All experiments were performed in triplicate, and numerical data were subjected to an independent-sample $t$-test or one-way ANOVA Kruskal-Wallis test. Mann-Whitney was used for comparison of RNA data $\left(2^{-\Delta \Delta \mathrm{Ct}}\right)$ with nonparametric data. The levels of significance were set at ${ }^{* * *} p \leq 0.0001,{ }^{* * *} p \leq 0.001,{ }^{* *} p \leq 0.01,{ }^{*} 0.01<p \leq 0.05$, and ns, $p>0.05$. Statistical analyses were performed using Statistical Package for the Social Science (SPSS, Chicago, IL, USA) version 22.0 and Graph Pad Prism 8 software. 


\section{Results}

\subsection{Bioinformatics-Based Retrieval of Noncoding RNAs}

To investigate the role of the circRNA-miRNA-mRNA regulatory axis in HCC, we performed an in silico networking analysis. We first searched for circRNA-associated competing endogenous RNA (ceRNA) relevant to HCC according to previous microarray studies. Firstly, we analyzed circRNA genes specific to HCC through circBase (available at http: / / www.circbase.org/, http:/ / circnet.mbc.nctu.edu.tw/), Aceessed on 28 November 2019) and Circ2Traits databases (available at http: / gyanxet-beta.com/circdb / , http: / / circnet. mbc.nctu.edu.tw/), Aceessed on 28 November 2019) and found hsa-circ-000520 $($ cirCtrait $)=h s a-$ circ-0000221 $($ cirBase $)=$ VIM to be highly relevant to HCC with one of the highest ranking scores (Figure S1, Supplementary Materials). Secondly, we analyzed circRNA-miRNA interaction databases, e.g., CircNet database (available at http: / / circnet.mbc.nctu.edu.tw /), Aceessed on 28 November 2019) to retrieve competing endogenous RNA specific for HCC and found hsa-mir-661 (Figure S2). Computational prediction of $h s a$-circ-0000221 target miRNAs revealed 40 possible interacting miRNAs with binding sites on the $h s a$-circ-0000221 transcript. The interaction of hsa-mir-661 was verified by the Circ2Trait database (Figure 1). The hsa-mir-661 interaction was further validated by performing pathway enrichment analysis using miRPath tool through mircoT-CDS [24] (set at a $p$-value threshold of 0.05). This revealed significant enrichment in the cancer metabolic pathway, Hippo signaling pathway, cGMP-PKG signaling pathway, mTOR signaling pathway, AMPL signaling pathway, TGF-beta signaling pathway, insulin signaling pathway pathways in cancer, inflammatory mediator regulation of TRP channels, focal adhesion, and Wnt signaling pathway. These signaling pathways are known to play an important role in HCC carcinogenesis.

miR-661 was predicted to be direct target of $h$ sa-circ-000022. Ontology analysis of hsa-mir-661 set revealed significant enrichment in G2/M transition of the mitotic cell cycle, apoptotic signaling pathway, cellular component disassembly involved in the execution phase of apoptosis, viral process, and cell death pathway These data are in agreement with gene ontology of $h$ sa-circ-0000221 and its possible role in HCC. Lastly, we selected PTPN mRNA as a direct target of mir-661 on the basis of TargetScan, miRwalk databases (Figure S3) and previous literature [25] that highlighted PTPN mRNA as a tumor suppressor gene involved in focal adhesion signaling, IKK/NF- $\mathrm{KB}$ signaling, cell proliferation, and gastrointestinal carcinogenesis. Prediction using the TargetScan tool revealed 6959 interacting mRNAs, while prediction using miRWalk revealed 57,601 interacting mRNAs. Both predictions were filtered according to prediction scores provided by both tools, and the top 100 interacting mRNAs were further considered for gene ontology and pathway enrichment analysis. The dataset of hsa-mir-661 target mRNAs was subjected to ontology prediction through WebGestalt tool [26], which uses GOSlim for ontology, showing significant enrichment in protein- and ion-binding functions (Figure 2A).

The main ontology terms determined by GOSlim were further inspected through the Enrichr tool. The pathway enrichment through the Panther database [27] showed remarkable enrichment in the Wnt pathway, which is crucial for HCC carcinogenesis. Other pathways were also significantly enriched including cadherin pathway and p53 signaling feedback loops (Figure 2B). The inspected biological process category showed positive regulation of viral transcription, apoptotic signaling, ERBB2 signaling, chemotaxis of immune cells, and ERK1 and ERK2 cascade, which has tumor-promoting effects in HCC. Inspection of cellular components revealed enrichment in CENP-A containing chromatin mitotic spindle polar microtubule and chromatin components. Additionally, molecular function ontology showed ATPase, phosphatase, DNA and RNA polymerase, and MAP kinase activity enrichment, which is strongly involved in HCC. Among these significantly interacting mRNAs, PTPN11 was predicted as the potential component of the ceRNA containing hsa-circ-0000221 and hsa-mir-661 in HCC.

Lastly, the STRING database was used to analyze the protein-protein interactions of PTPN11 (Figure 2C). It was interesting that PTPN11 was shown to exhibit a significant 
interaction with MAPK3 and EGFR, along with other less significant interactions with TP53, MTOR, JUN, and STAT1. These interactions may explain the role of PTPN11 in HCC, along with MAPK3 and EGFR, which are important players in HCC carcinogenesis as reported in the HCC pathways map in the KEGG database. These interactions were further investigated through ontology prediction on the STRING database analysis tab which showed significant enrichment in HCC-relevant biological processes including positive regulation of MAPK cascade and JAK/STAT cascade. Molecular function ontologies showed enrichment in kinase binding and protein kinase activity, while cellular component ontology showed enrichment in phosphatidylinositol 3-kinase complex and Shc-EGFR complex. KEGG pathway enrichment showed enrichment in pathways in cancer, as well as the proteoglycans in cancer pathway, Ras signaling pathway, PI3K/Akt signaling pathway, FoxO signaling pathway, TNF signaling pathway, nonalcoholic fatty liver disease (NAFLD), and hepatitis C, which is strongly associated with the development of HCC.

(A)

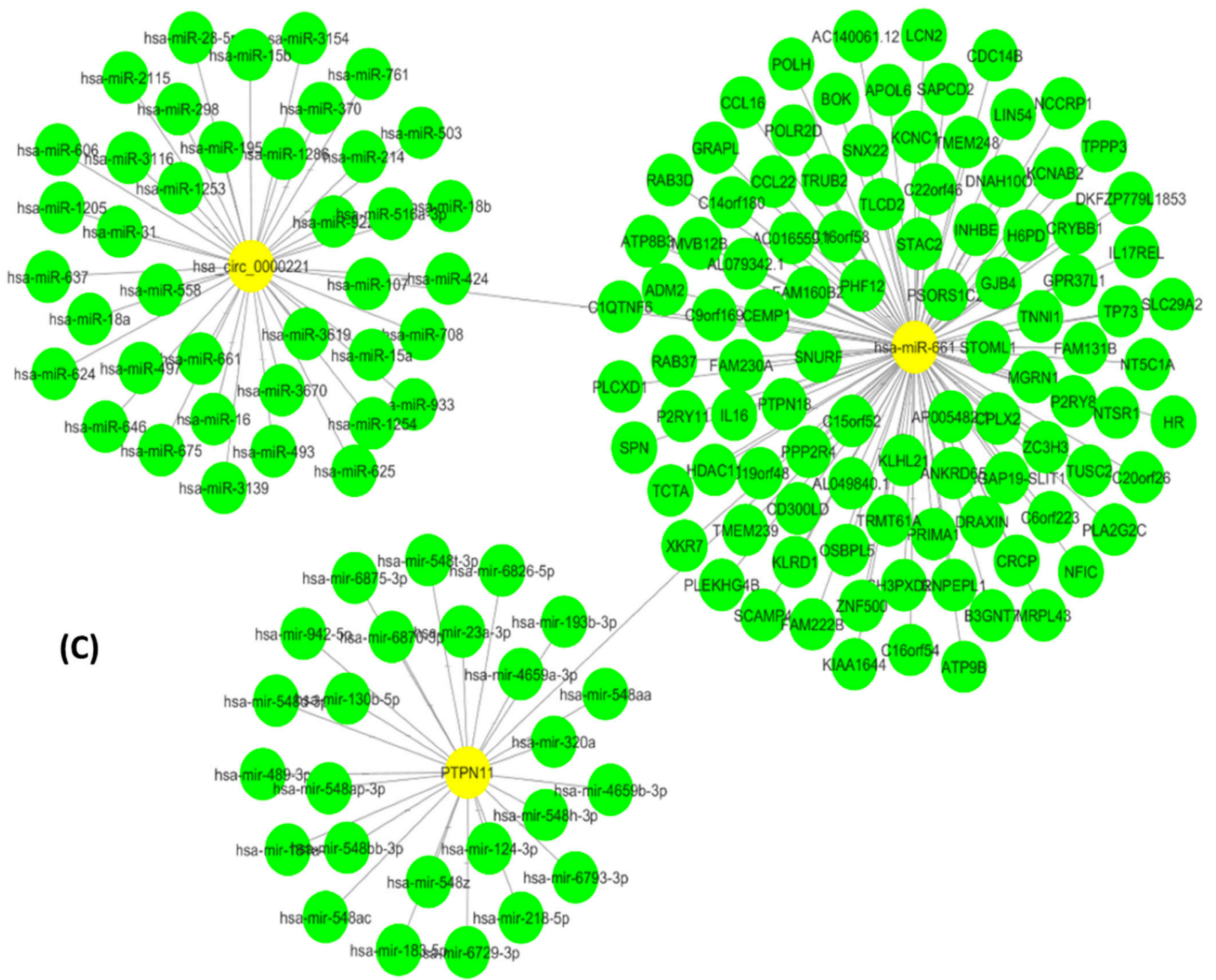

(B) 
A

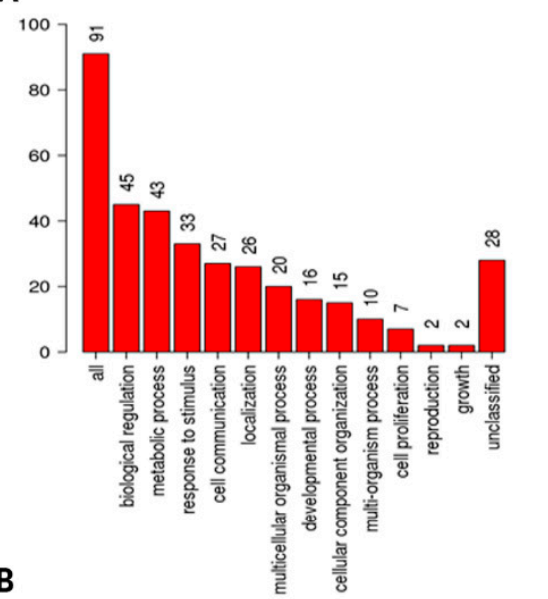

Cacherin signaling pathway_Homo sapiens_P00012

\section{Wnt signaling pathway_Homo sapiens_P00057}

Muscarinic acetylcholine refeptor 1 and 3 signaling pathway_Homo sapiens_P00042

Muscarinic acetylcholine receptor 2 and 4 signaling pathway_Homo sapiens_P00043

Nicotinic acetylcholine receptor signaling pathway_Homo sapiens_P00044

Synaptic vesicle trafficking_Homo sapiens_P05734

lonotropic glutamate receptor pathway_Homo sapiens_P00037

P53 pathway feedback loops 1_Homo sapiens_P04392

Metabotropic glutamate receptor group III pathway_Homo sapiens_P00039

B cell activation_Homo sapiens_P00010
Bar chart of Cellular Component categories

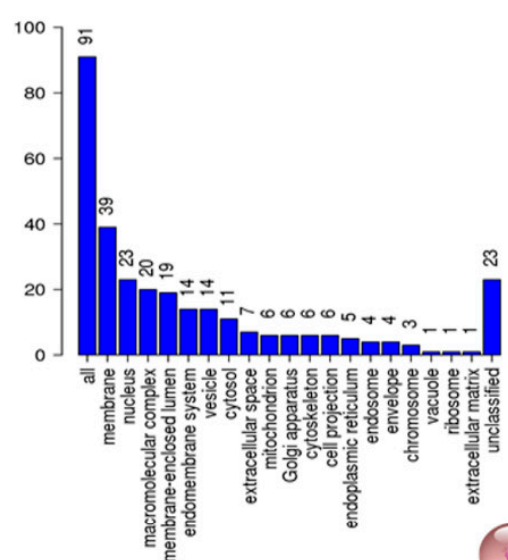

c

Bar chart of Molecular Function categories

$100]$ के
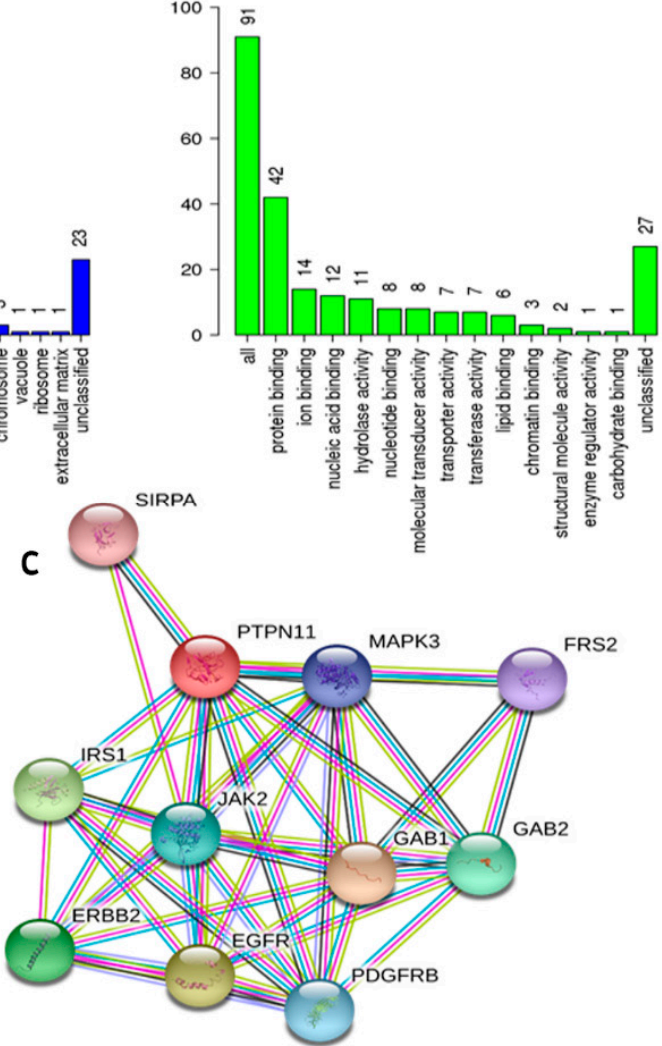

Figure 2. Gene ontology prediction for the $h s a$-circ-0000221 ceRNA network. (A) GOSlim ontology prediction summary for top 100 mRNA targets of hsa-mir-661 as predicted by the WebGestalt server. The three bar charts represent the main categories of gene ontology including biological process (red), cellular component (blue), and molecular function (green). (B) Significant Panther pathways predicted in which mRNA targets of hsa-mir-661 were enriched, as predicted using Enrichr. (C) STRING database network of PTPN11 significant protein-protein interactions.

\subsection{Expression of hsa-circ-0000221-miR-661-PTPN11 mRNA in Serum Samples}

To practically validate our molecular network, we decided to detect the expression of the hsa-circ-0000221, miR-661, and PTPN11 transcripts in the sera from a panel of HCC patients, chronic hepatitis $\mathrm{C}$ virus (HCV)-infected patients, and control volunteers. We included chronic HCV-positive patients since HCV infection is endemic in Egypt with the highest prevalence rate in the world [28], chronic HCV infection increases the risk for HCC by 15 - to 20 -fold, and it is reported that half of all HCC patients have serological evidence of HCV infection [29]. These patients suffered from chronic HCV infection; however, they did not develop HCC. On the other hand, some of the patients in the HCC group were $\mathrm{HCV}$-positive but with malignant transformation in the liver. Hence, it was interesting to investigate how the expression of the hsa-circ-0000221, miR-661, and PTPN11 transcripts would be altered in these three groups of patients. The detailed clinical data of the three studied groups are shown in Table 1. Quantitative RT-PCR data of those tested RNAs revealed that the expression of $h$ sa-circ-0000221 and PTNPN 11 mRNA in HCC patients was significantly (10-fold and threefold, respectively) lower compared with their expression in the control group ( $p \leq 0.0001$ and $p \leq 0.01$, respectively) (Figure 3A,C). Moreover, the relative expression level of miR-661 was significantly elevated (22-fold) in the HCC group compared with its expression in the control group $(p<0.05)$ (Figure 3B). 

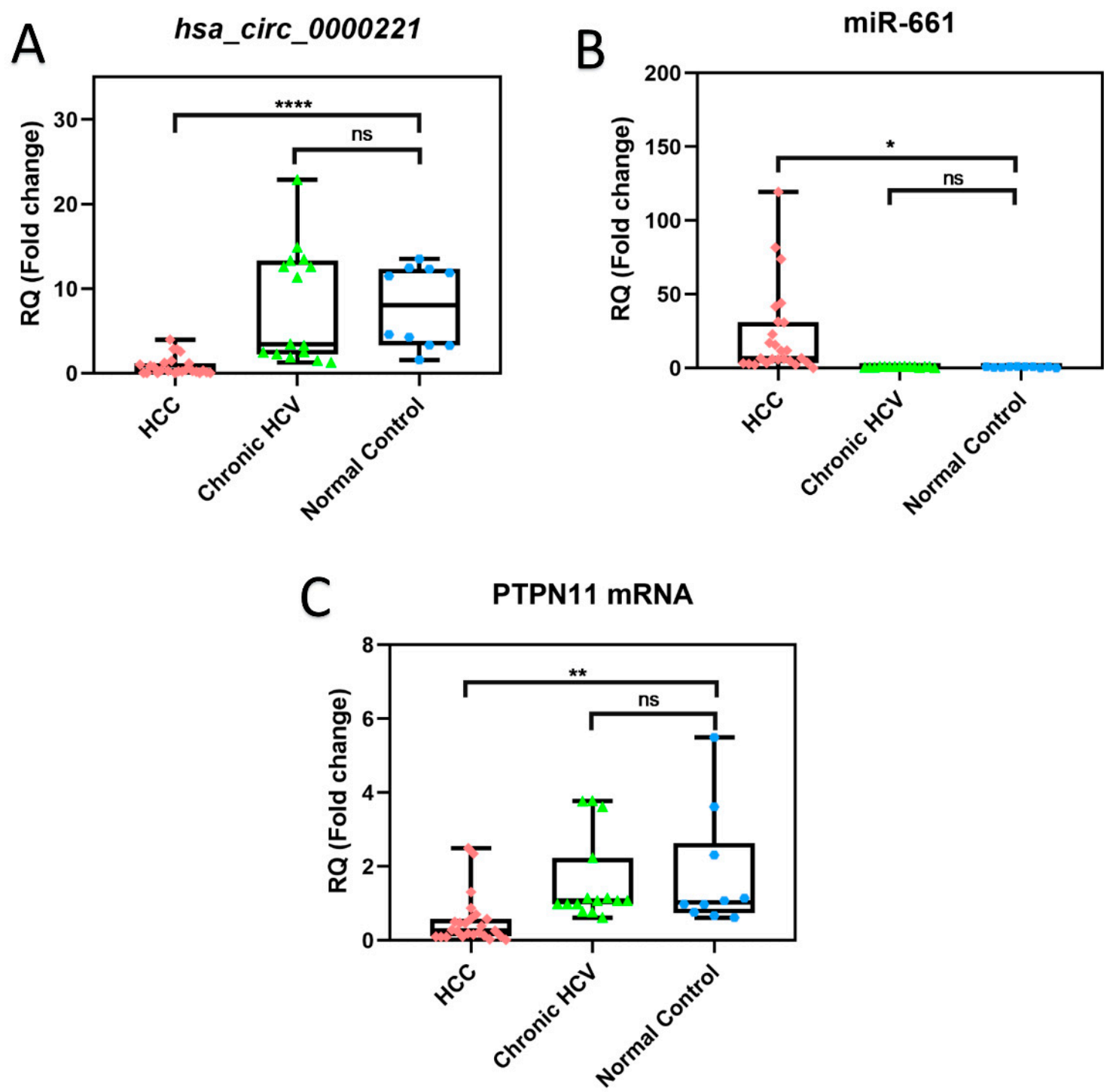

Figure 3. Expression of serum hsa-circ-0000221, miR-661, and PTPN 11 mRNA as determined by qRT-PCR in HCC, chronic HCV, and healthy individuals. The boxplots show the expression of serum (A) hsa-circ-0000221, (B) miR-661, and (C) PTPN11 mRNA among three patient groups: HCC, chronic $\mathrm{HCV}$, and normal control. Individual data points represent individual patients in each group, while error bars indicate SD. Statistics were performed using Student's unpaired $t$-test; ${ }^{* * * *} p \leq 0.0001$, ** $p \leq 0.01,{ }^{*} 0.01<p \leq 0.05$, and ns, $p>0.05$.

To further investigate the link of these molecular network members in vitro, we overexpressed the $h s a$-circ-0000221 in two representative HCC cell lines, HepG2 and SNU449. qRT-PCR of the three RNAs in HepG2 showed that the expression of hsa-circ-0000221 increased (threefold) 2 days after transfection compared with that of day 1 . Our results showed that the upregulation of $h s a$-circ-0000221 was significantly associated with inhibition of miR-661 expression (about fourfold lower, $p<0.01$ ) and upregulation of PTPN11 mRNA $(p<0.05)$ (Figure 4A). A similar effect was observed in SNU449 cells where again the upregulation of $h$ sa-circ-0000221 caused an inhibition in miR-661 expression and upregulation of the PTPN11 mRNA levels (Figure 4B). This in turn inversely correlated with the cellular viability and the number of living HepG2 cells (Figure 4B,C respectively) and SNU449 cells (Figure 4E). These results indicate that hsa-circ-0000221 may mediate PTPN 11 upregulation and subsequently show toxic effects in HCC cells. 

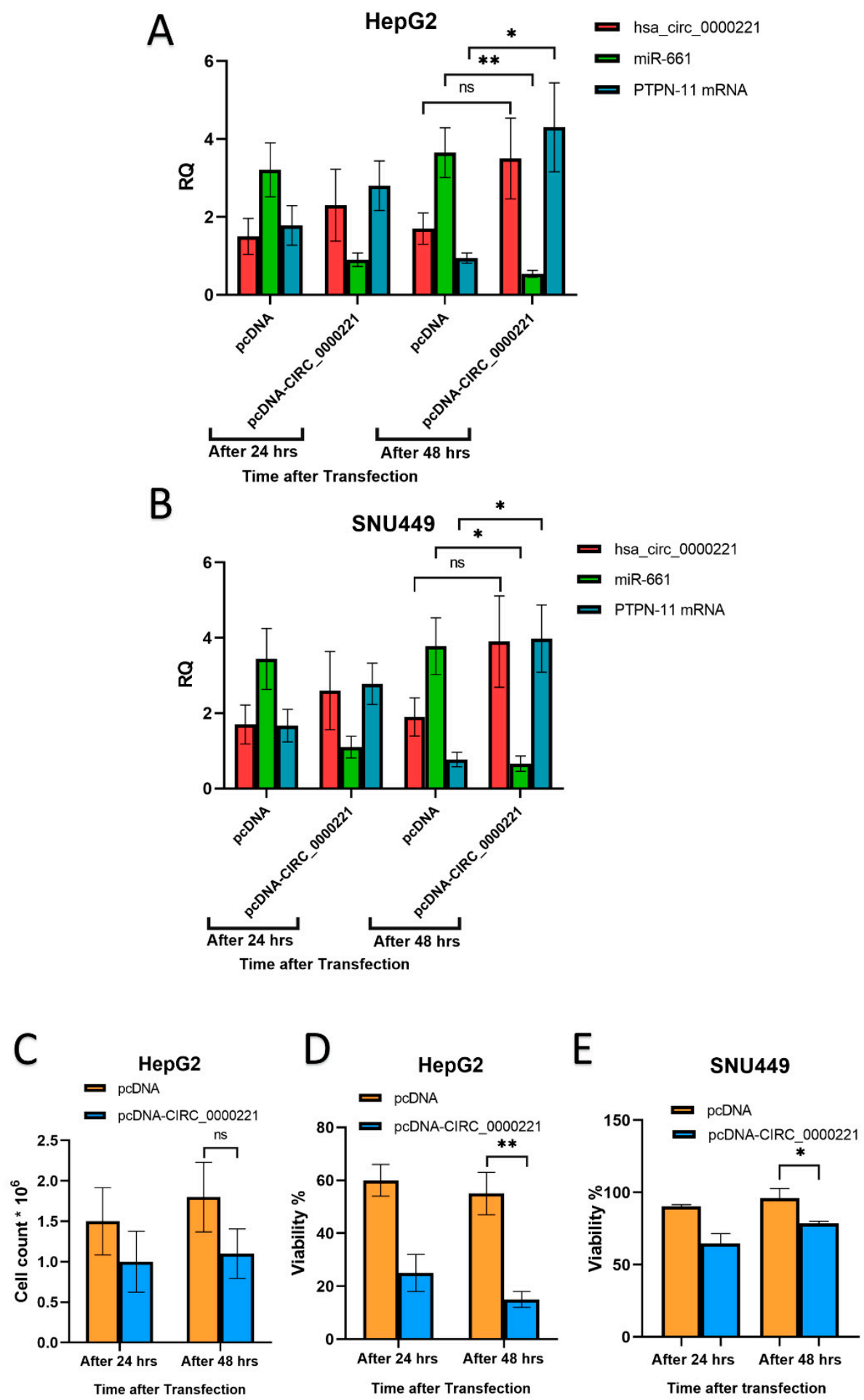

Figure 4. Effect of $h s a \_c i r c \_0000221$ overexpression in HepG2 and SNU449 cells. hsa_circ_0000221, miR-661, and PTPN 11 mRNA were quantified by qRT-PCR 1 and 2 days after transfection of either pcDNA-CIRC-0000221 or control vector in (A) HepG2 and (B) SNU449 cell lines. Data for each gene were normalized to their counterparts in cells at $0 \mathrm{~h}$. (C) Cell count in HepG2 cells, and cellular viability in (D) HepG2 and (E) SNU449 cells were measured 1 and 2 days after transfection. Error bars represent SD. Statistics were performed using Student's unpaired $t$-test; ${ }^{* *} p \leq 0.01,{ }^{*} 0.01<p \leq 0.05$, and ns, $p>0.05$. 


\section{3. hsa-circ-0000221 Induces Apoptosis in HCC}

To investigate whether the expression of hsa-circ-0000221 is inducing necrotic or apoptotic cell death, SNU449 cells were transfected (transfection efficiency was more than $50 \%$ ) with hsa-circ-0000221 expressing plasmid or control. Cells expressing the circRNA showed cellular death, which was detected by rounding cells that detach plastic as shown by regular microscopy (Figure 5A). Furthermore, exogenous expression of this gene also significantly reduced the colony-forming ability of the SNU449 and HepG2 cells as quantified in Figure 5B,C. Representative images of the assay are shown in Supplementary Figure S4. Lastly, the number of annexin V-stained cells was significantly enhanced by transient transfection with $h s a$-circ-0000221 in both cell lines, indicating that the observed cell death is due to apoptosis (Figure 5D,E).

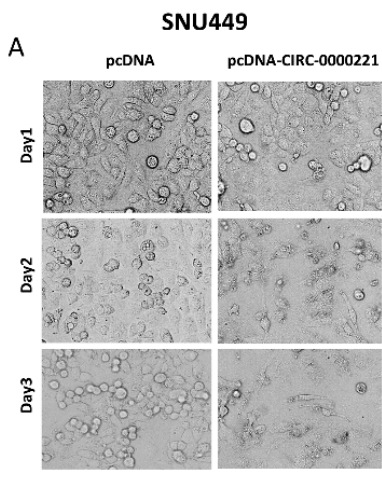

B
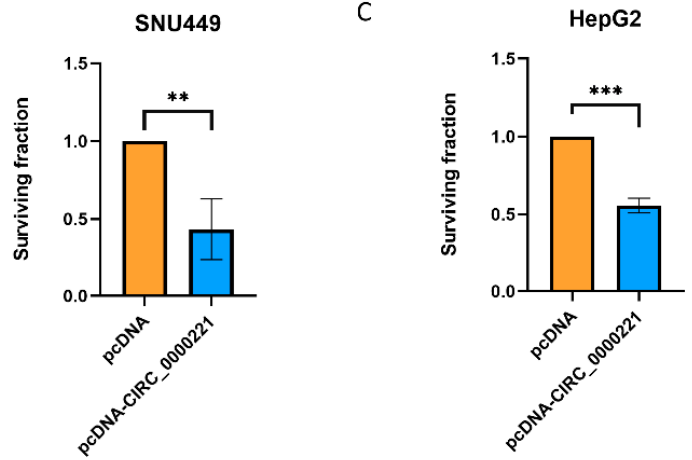

D
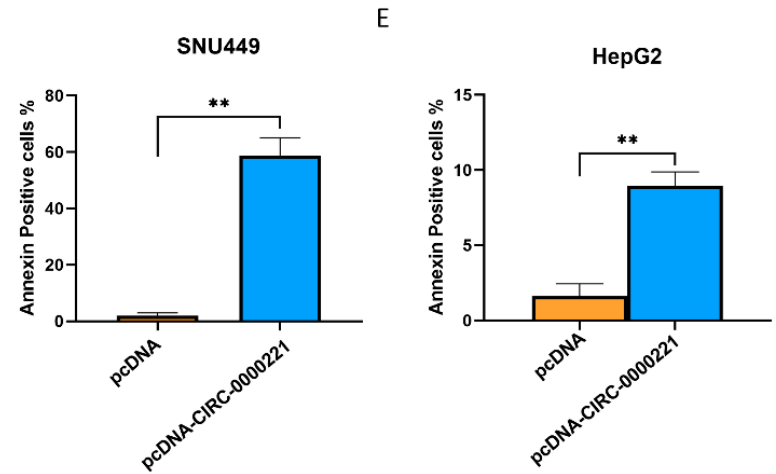

Figure 5. Exogenous expression of $h s a$-circ-0000221 induces apoptosis in HepG2 and SNU449 cells. (A) Phase contrast of SNU449 cells 1, 2, and 3 days after transient transfection with hsa-circ-0000221expressing vector or control. Clonogenic survival assay of (B) SNU449 and (C) HepG2 cells after overexpression of $h s a$-circ-0000221 or empty vector reflecting the differential colony-forming ability between the two conditions as indicated by the surviving fraction. Annexin-positive cell percentage as determined by flow cytometry of (D) SNU449 and (E) HepG2 cells after overexpression of $h s a-$ circ-0000221 or empty vector following annexin $\mathrm{V}$ and propidium iodide staining. Statistics were performed using Student's unpaired $t$-test; ${ }^{* *} p \leq 0.01,{ }^{* * *} p \leq 0.001$. 


\section{4. hsa-circ-0000221 Disturbs Cell Cycle and Induces Caspase-Dependent Apoptosis in HCC}

To further investigate the mechanism through which hsa-circ-0000221 affects the viability and induces apoptosis in HCC, we studied the cell cycle after transfection with hsa-circ-0000221-expressing vector or empty vector. The DNA content study indicates that SNU449 cells overexpressing hsa-circ-0000221 are relatively accumulated in the G1 phase, and those that are released from the G2/M phase hardly re-enter the cell cycle and may face cell death as indicated by the different population in the cytograph (Figure 6A left) and the quantification performed for all repeats (Figure 6A right). The debris peak indicating dead cells appeared as a sub-G1 peak only in those cells overexpressing the circRNA but not in the mock-treated cells.

A

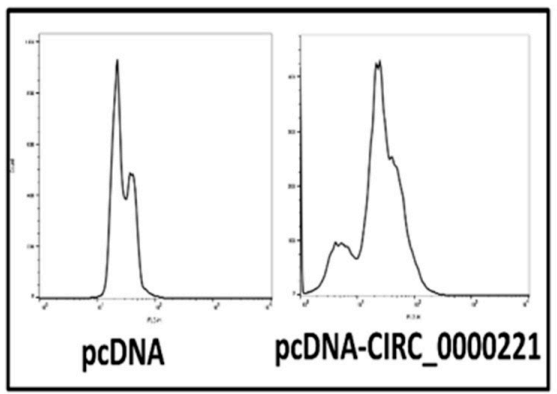

Cell Cycle phases (\%)
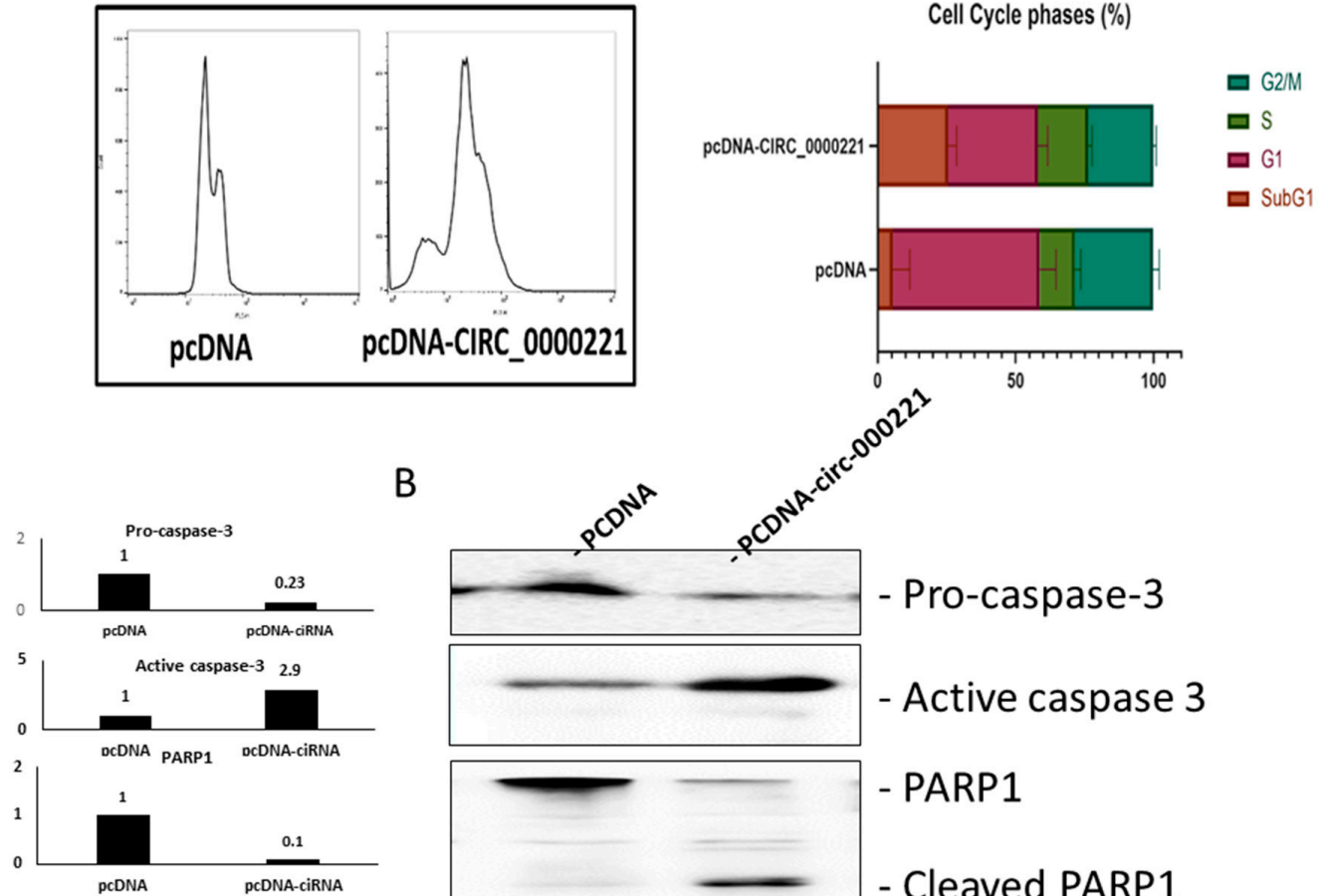

B
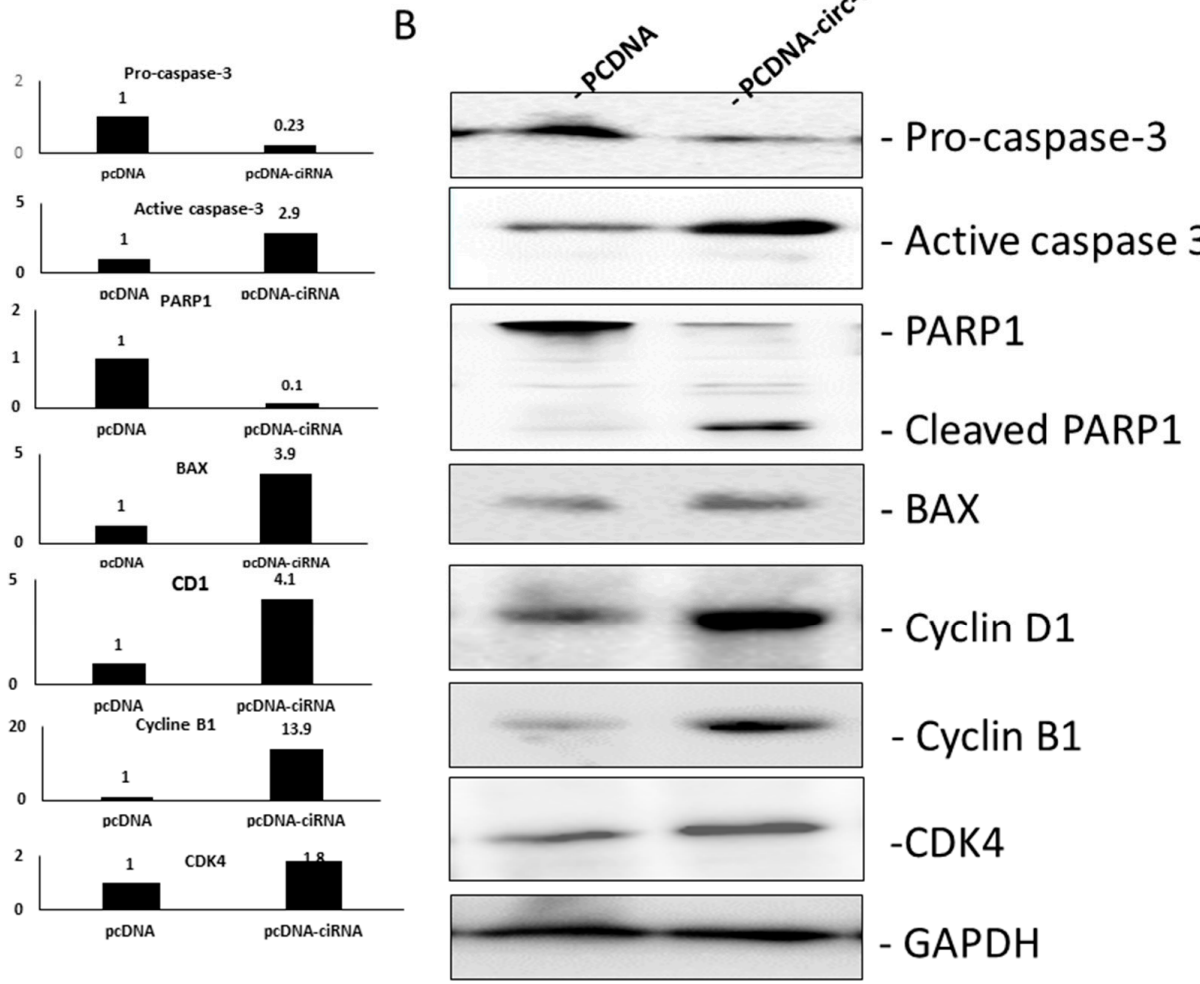

- Cyclin D1

- Cyclin B1

\section{-CDK4}

\section{- GAPDH}

Figure 6. hsa-circ-0000221 overexpression induces cell-cycle arrest and caspase-dependent apoptosis. (A) Representative FACS analysis of SNU449 cells after transient transfection with hsa-circ-0000221expressing vector or backbone (left). Quantification of cell-cycle phases in each condition (right). The cells overexpressing hsa-circ-0000221 showed accumulation in the G1 phase compared with mock. Error bars represent SD. (B) Western blotting analysis (left) of the same two clones as above, showing the effect of $h$ sa-circ-0000221 overexpression on procaspase-3, caspase-3, PARP1, CB1, CCDN1, CDK4, and Bax. GAPDH was also detected as a loading control. Quantification of the bands for each blot and each condition is shown (right). AU: arbitrary units. 
To further investigate the mechanism of cellar death by hsa-circ-0000221, we studied the expression of a panel of apoptosis/cell cycle-related molecules (Figure 6B). Importantly, SNU449 cells overexpressing hsa-circ-0000221 showed the accumulation of cyclin B1, cyclin D1, and CDK4, indicating prevention of S phase entry. Moreover, typical molecular signs of apoptosis were observed including PARP1 cleavage, pro-caspase depletion, and active caspase accumulation in those cells overexpressing hsa-circ-0000221. Lastly, apoptosis was shown to be mitochondrial-dependent because the proapoptotic effector protein BAX was significantly upregulated in the tested cells.

\section{Discussion}

Although circRNAs were treated as transcriptional noise since they were first discovered in 1979 [30], their role in disease development and particularly in tumorigenesis of different forms of cancer has been gaining more interest [31]. For example, a database of circRNAs directly detected in prostate cancer tissues has been recently curated and termed MiOncoCirc [9]. In this study, we focused on the role of circRNAs in HCC, which may lead to a better understanding of the molecular mechanism of HCC carcinogenesis and could contribute to enhancing diagnostic and/or therapeutic strategies [32-34].

Our in silico investigation revealed a novel molecular network in HCC of hsa-circ0000221-miR-661-PTPN11 mRNA. This molecular network, to the best of our knowledge, is reported here for the first time. We used a panel of serum samples from HCC patients, chronically infected HCV patients, and normal volunteers, of different ages and sex, to validate this network. We found that $h s a$-circ-0000221 was significantly depleted in the sera of HCC patients compared to normal controls and HCV patients. These depleted levels were associated with a high expression pattern of miR-661 and low expression of PTPN11 transcripts in the serum, which is contrary to the case of patients with nonmalignant livers (both normal controls and HCV patients). These data suggest that hsa-circ-0000221 and, consequently, the hsa-circ-0000221-miR-661-PTPN11 mRNA axis are deregulated specifically in malignancy and not with viral infection of the liver, even though HCV infection is a well-documented cause of HCC. Previous reports have shown that HCV can modulate the abundance of some circRNAs in infected cells [35]. Although this is not apparent for hsa-circ-0000221 levels in serum, it would be interesting in the future to investigate whether its expression is affected in liver cells upon HCV infection. This is the first report showing a role for $h s a$-circ-0000221 and its deregulation in cancer. The hsa-circ-0000221-miR-661-PTPN11 mRNA axis was validated to be present in both HCC cell lines tested, indicating that it could be a key player in HCC pathogenesis.

miR-661 can be oncogenic or tumor-suppressive in cancer development [36,37]. It has been reported to be deregulated in breast cancer [38] and ovarian cancer [39], while a recent report showed its role in $\mathrm{HCC}$, where a significant correlation was found between the levels of miR-661 and the expression of NF-kB-p65 and hepatitis B virus transactivator protein (HBx) in a human HCC cell line through HBx-mediated stimulation of metastasis-associated protein 1 (MTA1) [40].

According to our findings, miR-661 has an oncogenic function in HCC as it targets PTPN11; depletion of miR-661 may give the chance for PTPN11 transcript to increase and subsequently inhibit cellular proliferation in HCC. Our results proved that miR-661 could be depleted indirectly via upregulation or overexpression of hsa-circ-0000221 in HCC cells. Furthermore, our finding indicates that miR-661 depletion and the subsequent increase in PTPN11 are a consequence of $h$ sa-circ-0000221 overexpression in vitro, which is associated with retardation of the cellular viability and/or apoptosis induction.

PTPN11/Shp2 is an intracellular tyrosine phosphatase with two Src-homology 2 (SH2) domains [25] that acts to promote activation of the Ras/ERK pathway by cytokines, growth factors, and hormones. PTPN11 mutations have been linked to juvenile myelomonocytic leukemia (JMML) [41], colorectal cancer [42], breast cancer [43], and HCC [44]. The tumor-suppressive role of PTPN11 in HCC is mediated through the I $\kappa$ B kinase/NF- $\kappa$ B (IKK/NF-KB) pathway through promoting IL-6-stimulated Stat3 activation $[45,46]$. Thus, 
the hsa-cir-0000221-miR-661-PTPN11 mRNA axis could be working through the IKK/ NF-kB pathway to inhibit cancerous proliferation.

Interestingly, other circular RNAs and microRNAs act as post-transcriptional modifiers of genes linked to the IKK/NF-кB signaling pathway in the liver [47]. Moreover, dysregulation of the IKK-NF- $\mathrm{KB}-\mathrm{IL}-6$ signaling pathway has been linked to the development of HCC $[48,49]$.

Our study uncovered the possible effect of $h s a$-circ-0000221 on HCC. The therapeutic efficacy of exogenously expressed $h$ sa-circ-0000221 in HCC cell lines was also evaluated. Our results showed that the upregulated $h$ sa-circ-0000221 expression is significantly associated with inhibition of miR-661 expression and upregulation of PTPN11 mRNA, which in turn inversely correlated with HCC cell viability and induced mitochondrial-dependent and caspase-dependent apoptosis. However, it needs to be noted that those phenotypic effects in HCC cells cannot be attributed directly to changes in miR-661 or PTPN11 levels as this was not experimentally validated in our study. Further investigation involving miRNA mimics or PTPN11 knockdown should be performed in future studies. CircRNAs are well known for being more stable than other RNA species in the cellular cytoplasm, exhibiting longer half-lives due to their covalently closed circular structure. They are resistant to RNase $\mathrm{R}$ and other exonucleases [50]. Moreover, due to this feature, circRNAs are very prevalent in blood, serum, and other body fluids such as interstitial fluid, saliva, and cerebrospinal fluid, making them ideal molecular biomarkers for several diseases [51]. Robust identification and quantification of their levels in patient samples by next-generation sequencing technologies have been shown [51-53]. Moreover, targeting miRNAs in vivo in HCV-infected nonhuman primates has been established [54], and the use of miRNA antagomirs for cancer treatment has been shown [55].

On the basis of the aforementioned findings, we adopted an integrative approach combining in silico data analysis with clinical and experimental validation. A reasonable interpretation of our hypothesis is that $h s a$-circ-0000221 competes with miR-661 and probably sponges miR-661 to modulate the expression of PTPN11 mRNA that is closely linked to the I $\mathrm{kB}$ kinase/NF- $\mathrm{kB}$ signaling pathway, which in turn affects the apoptosis pathway in the liver [56].

Taken together, we think that the depletion of hsa-circ-0000221 in the HCC patients' sera is a stable serum biomarker for HCC diagnosis with high resistance to the exonuclease RNase and a potential candidate for translation to be an effective therapeutic target, thereby improving the prognosis and survival rate of HCC patients. Introducing $h$ sa-circ-0000221 into HCC cells or tissues may be a promising therapeutic strategy (Figure 7). 

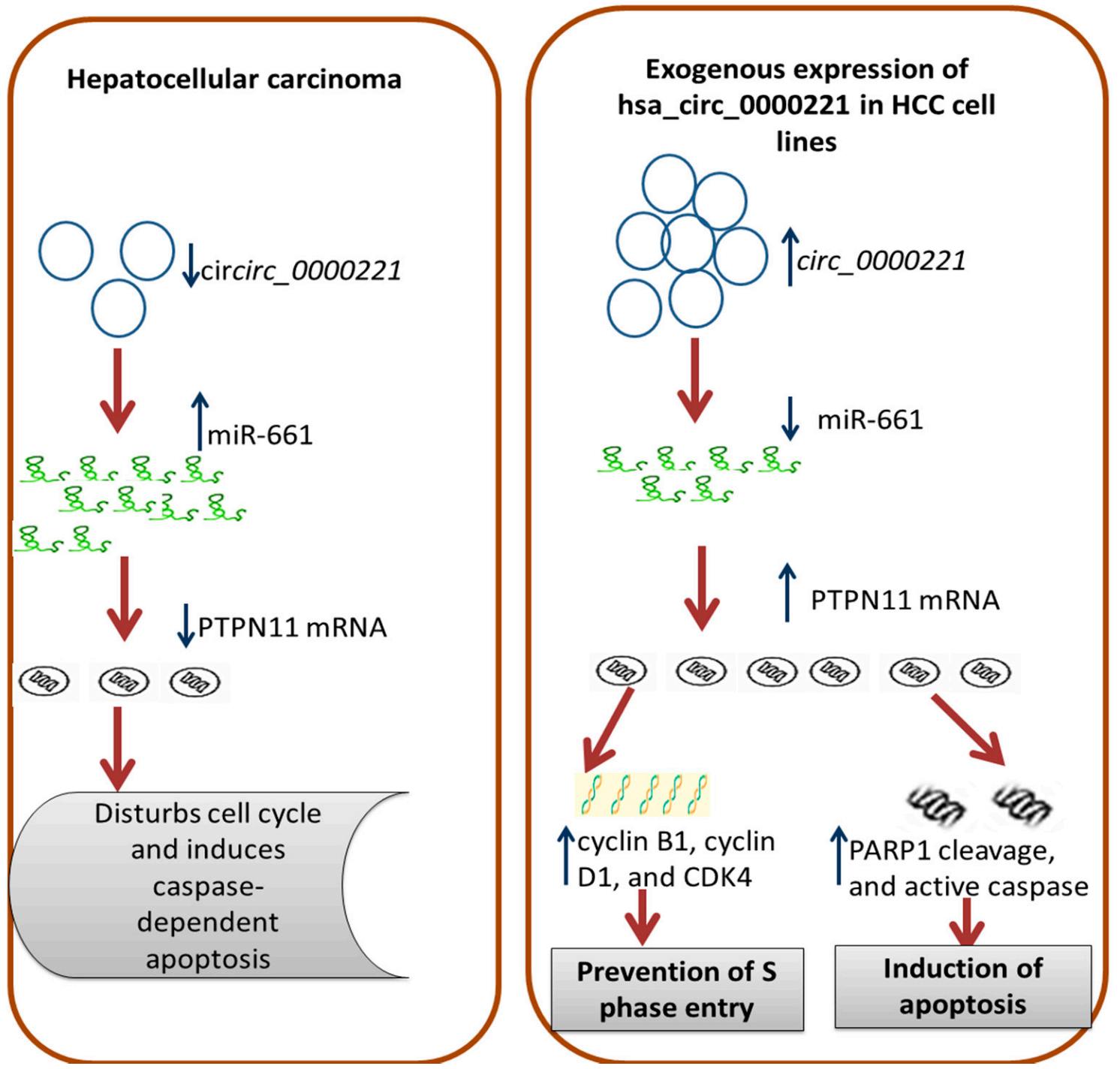

Figure 7. Schematic figure summarizing the role of hsa-circ-0000221-miR-661-PTPN11 mRNA in HCC.

\section{Conclusions}

The current study could lay the foundation for revealing the crucial roles of hsa-circ0000221 in HCC development and prognosis, paving the way toward better diagnostic and/or therapeutic strategies for better HCC management. This study was limited by its small sample size as an initial screening group, which was not sufficiently powered to examine the diagnostic efficacy of the chosen biomarkers. Therefore, further large multicenter studies are strongly recommended to evaluate the performance characteristics of the chosen RNA network. More in vitro mechanistic studies are need to highlight the underlying in-depth mechanism beyond the role of the chosen circular RNA network in HCC due to complexity of the circRNA intracellular mechanism of action.

Supplementary Materials: The following supporting information can be downloaded at https: //www.mdpi.com/article/10.3390/pharmaceutics14010138/s1: Figure S1. Print screen Shot Shot hsa_circ_000022 predicted by Circ 2 trait, Figure S2. Print screen Shot Shot hsa_circ_000022 \& miR-661 predicted by Circ 2, Figure S3. Print screen Shot fot miR-661\& PTPN-11 predicted by Target scan; Figure S4. Exogenous expression of hsa_circ_000022 significantly reduced the colony-forming ability of the SNU449 and HepG2 cells. 


\begin{abstract}
Author Contributions: Conceptualization, data curation, validation, writing draft, and supervision, M.M. and M.K.H.; methodology and investigation, M.A.A. and M.T.M.; methodology, writing original draft, and reviewing, W.E. and R.A.; investigation, visualization and drafting, H.S.A., M.E.M. and H.E.; project management and resources, S.E.-K.; formal analysis and reviewing, and supervision, S.H.A.A. funding acquisition, project management and supervision. All authors have read and agreed to the published version of the manuscript.
\end{abstract}

Funding: This study was supported by the Science and Technology Development Fund (STDF), BARG call 7, Project ID: 38135, and by the Center for Genomic, Zewail City for Science and Tech., Egypt.

Institutional Review Board Statement: The study was approved by the Ain Shams Research Ethics Committee, Faculty of Medicine, Egypt, FMASU MD 32/2016, in accordance with the guidelines of the Declaration of Helsinki.

Informed Consent Statement: Informed consent was obtained from all participants involved in the study.

Data Availability Statement: The data reported in this study are available on request from the corresponding authors.

Conflicts of Interest: The authors declare no conflict of interest.

\title{
References
}

1. Rashed, W.M.; Kandeil, M.A.M.; Mahmoud, M.O.; Ezzat, S. Hepatocellular carcinoma (HCC) in Egypt: A comprehensive overview. J. Egypt. Natl. Cancer Inst. 2020, 32, 5. [CrossRef]

2. Ali, H.S.; Boshra, M.S.; El Meteini, M.S.; Shafei, A.E.-S.; Matboli, M. lncRNA- RP11-156p1.3, novel diagnostic and therapeutic targeting vi CRISPR/Cas9 editing in hepatocellular carcinoma. Genomics 2020, 112, 3306-3314. [CrossRef]

3. Wei, L.; Wang, X.; Lv, L.; Liu, J.; Xing, H.; Song, Y.; Xie, M.; Lei, T.; Zhang, N.; Yang, M. The emerging role of microRNAs and long noncoding RNAs in drug resistance of hepatocellular carcinoma. Mol. Cancer 2019, 18, 147. [CrossRef]

4. Xu, J.; Ji, L.; Liang, Y.; Wan, Z.; Zheng, W.; Song, X.; Gorshkov, K.; Sun, Q.; Lin, H.; Zheng, X.; et al. CircRNA-SORE mediates sorafenib resistance in hepatocellular carcinoma by stabilizing YBX1. Signal Transduct. Target. Ther. 2020, 5, 298. [CrossRef] [PubMed]

5. Memczak, S.; Jens, M.; Elefsinioti, A.; Torti, F.; Krueger, J.; Rybak, A.; Maier, L.; Mackowiak, S.D.; Gregersen, L.H.; Munschauer, M.; et al. Circular RNAs are a large class of animal RNAs with regulatory potency. Nature 2013, 495, 333-338. [CrossRef]

6. Zhou, X.Y.; Yang, H.; Bai, Y.Q.; Li, X.L.; Han, S.Y.; Zhou, B.X. hsa_circ_0006916 promotes hepatocellular carcinoma progression by activating the miR-337-3p/STAT3 axis. Cell Mol. Biol. Lett. 2020, 25, 47. [CrossRef] [PubMed]

7. Jeck, W.R.; Sorrentino, J.A.; Wang, K.; Slevin, M.K.; Burd, C.E.; Liu, J.; Marzluff, W.F.; Sharpless, N.E. Circular RNAs are abundant, conserved, and associated with ALU repeats. RNA 2013, 19, 141-157. [CrossRef]

8. Mirzaei, S.; Zarrabi, A.; Hashemi, F.; Zabolian, A.; Saleki, H.; Ranjbar, A.; Saleh, S.H.S.; Bagherian, M.; Sharifzadeh, S.O.; Hushmandi, K.; et al. Regulation of Nuclear Factor-KappaB (NF-кB) signaling pathway by non-coding RNAs in cancer: Inhibiting or promoting carcinogenesis? Cancer Lett. 2021, 509, 63-80. [CrossRef] [PubMed]

9. Vo, J.N.; Cieslik, M.; Zhang, Y.; Shukla, S.; Xiao, L.; Zhang, Y.; Wu, Y.-M.; Dhanasekaran, S.M.; Engelke, C.G.; Cao, X.; et al. The landscape of circular RNA in cancer. Cell 2019, 176, 869-881.e13. [CrossRef] [PubMed]

10. Hussen, B.M.; Honarmand Tamizkar, K.; Hidayat, H.J.; Taheri, M.; Ghafouri-Fard, S. The role of circular RNAs in the development of hepatocellular carcinoma. Pathol. Res. Pract. 2021, 223, 153495. [CrossRef] [PubMed]

11. Zhang, H.; Cai, K.; Wang, J.; Wang, X.; Cheng, K.; Shi, F.; Jiang, L.; Zhang, Y.; Dou, J. miR-7, inhibited indirectly by LincRNA HOTAIR, directly inhibits SETDB1 and reverses the EMT of breast cancer stem cells by downregulating the STAT3 pathway. Stem Cells 2014, 32, 2858-2868. [CrossRef]

12. Fang, Y.X.; Xue, J.-L.; Shen, Q.; Chen, J.; Tian, L. MicroRNA-7 inhibits tumor growth and metastasis by targeting the phosphoinositide 3-kinase/ Akt pathway in hepatocellular carcinoma. Hepatology 2012, 55, 1852-1862. [CrossRef] [PubMed]

13. Ghosal, S.; Das, S.; Sen, R.; Basak, P.; Chakrabarti, J. Circ2Traits: A comprehensive database for circular RNA potentially associated with disease and traits. Front. Genet. 2013, 4, 283. [CrossRef]

14. Liu, Y.-C.; Li, J.-R.; Sun, C.-H.; Andrews, E.; Chao, R.-F.; Lin, F.-M.; Weng, S.-L.; Hsu, S.-D.; Huang, C.-C.; Cheng, C.; et al. CircNet: A database of circular RNAs derived from transcriptome sequencing data. Nucleic Acids Res. 2015, 44, D209-D215. [CrossRef] [PubMed]

15. Dudekula, D.B.; Panda, A.C.; Grammatikakis, I.; De, S.; Abdelmohsen, K.; Gorospe, M. CircInteractome: A web tool for exploring circular RNAs and their interacting proteins and microRNAs. RNA Biol. 2016, 13, 34-42. [CrossRef]

16. Agarwal, V.; Bell, G.W.; Nam, J.-W.; Bartel, D.P. Predicting effective microRNA target sites in mammalian mRNAs. eLife 2015, 4, e05005. [CrossRef] 
17. Dweep, H.; Gretz, N. miRWalk2.0: A comprehensive atlas of microRNA-target interactions. Nat. Methods 2015, 12, 697. [CrossRef] [PubMed]

18. Shannon, P.; Markiel, A.; Ozier, O.; Baliga, N.S.; Wang, J.T.; Ramage, D.; Amin, N.; Schwikowski, B.; Ideker, T. Cytoscape: A Software environment for integrated models of biomolecular interaction networks. Genome Res. 2003, 13, 2498-2504. [CrossRef]

19. Szklarczyk, D.; Morris, J.H.; Cook, H.; Kuhn, M.; Wyder, S.; Simonovic, M.; Santos, A.; Doncheva, N.T.; Roth, A.; Bork, P.; et al. The STRING database in 2017: Quality-controlled protein-protein association networks, made broadly accessible. Nucleic Acids Res. 2017, 45, D362-D368. [CrossRef] [PubMed]

20. Vlachos, I.S.; Zagganas, K.; Paraskevopoulou, M.D.; Georgakilas, G.; Karagkouni, D.; Vergoulis, T.; Dalamagas, T.; Hatzigeorgiou, A.G. DIANA-miRPath v3.0: Deciphering microRNA function with experimental support. Nucleic Acids Res. 2015, 43, W460-W466. [CrossRef]

21. Zhang, B.; Kirov, S.; Snoddy, J. WebGestalt: An integrated system for exploring gene sets in various biological contexts. Nucleic Acids Res. 2005, 33, W741-W748. [CrossRef]

22. Zhang, L.; Qu, S.; Liang, A.; Jiang, H.; Wang, H. Gene expression microarray analysis of the sciatic nerve of mice with diabetic neuropathy. Int J Mol Med. 2015, 35, 333-339. [CrossRef]

23. Livak, K.J.; Schmittgen, T.D. Analysis of Relative Gene Expression Data Using Real-Time Quantitative PCR and the $2-\Delta \Delta C T$ Method. Methods 2001, 25, 402-408. [CrossRef] [PubMed]

24. Paraskevopoulou, M.D.; Georgakilas, G.; Kostoulas, N.; Vlachos, I.S.; Vergoulis, T.; Reczko, M.; Filippidis, C.; Dalamagas, T.; Hatzigeorgiou, A.G. DIANA-microT web server v5.0: Service integration into miRNA functional analysis workflows. Nucleic Acids Res. 2013, 41, W169-W173. [CrossRef]

25. Cheng, J.; Luan, J.; Chen, P.; Kuang, X.; Jiang, P.; Zhang, R.; Chen, S.; Cheng, F.; Gou, X. Immunosuppressive receptor LILRB1 acts as a potential regulator in hepatocellular carcinoma by integrating with SHP1. Cancer Biomark. 2020, 28, 309-319. [CrossRef]

26. Hansen, T.B.; Jensen, T.I.; Clausen, B.H.; Bramsen, J.B.; Finsen, B.; Damgaard, C.K.; Kjems, J. Natural RNA circles function as efficient microRNA sponges. Nature 2013, 495, 384-388. [CrossRef]

27. Mi, H.; Huang, X.; Muruganujan, A.; Tang, H.; Mills, C.; Kang, D.; Thomas, P.D. PANTHER version 11: Expanded annotation data from Gene Ontology and Reactome pathways, and data analysis tool enhancements. Nucleic Acids Res. 2016, 45, D183-D189. [CrossRef]

28. Elgharably, A.; Gomaa, A.; Crossey, M.M.E.; Norsworthy, P.J.; Waked, I.; Taylor-Robinson, S.D. Hepatitis C in Egypt-Past, present, and future. Int. J. Gen. Med. 2016, 10, 1-6. [CrossRef] [PubMed]

29. El-Serag, H.B. Epidemiology of hepatocellular carcinoma in USA. Hepatol. Res. 2007, 37, S88-S94. [CrossRef] [PubMed]

30. Hsu, M.-T.; Coca-Prados, M. Electron microscopic evidence for the circular form of RNA in the cytoplasm of eukaryotic cells. Nature 1979, 280, 339-340. [CrossRef]

31. Shao, Y.; Li, J.; Lu, R.; Li, T.; Yang, Y.; Xiao, B.; Guo, J. Global circular RNA expression profile of human gastric cancer and its clinical significance. Cancer Med. 2017, 6, 1173-1180. [CrossRef] [PubMed]

32. Li, P.; Chen, S.; Chen, H.; Mo, X.; Li, T.; Shao, Y.; Xiao, B.; Guo, J. Using circular RNA as a novel type of biomarker in the screening of gastric cancer. Clin. Chim. Acta 2015, 444, 132-136. [CrossRef]

33. Jin, J.; Liu, H.; Jin, M.; Li, W.; Xu, H.; Wei, F. Silencing of hsa_circ_0101145 reverses the epithelial-mesenchymal transition in hepatocellular carcinoma via regulation of the miR-548c-3p/LAMC2 axis. Aging 2020, 12, 11623-11635. [CrossRef] [PubMed]

34. Ely, A.; Bloom, K.; Maepa, M.B.; Arbuthnot, P. Recent Update on the Role of Circular RNAs in Hepatocellular Carcinoma. J. Hepatocell. Carcinoma 2021, 8, 1-17. [CrossRef]

35. Chen, J.; Zhao, X.; Yuan, Y.; Jing, J.-J. The expression patterns and the diagnostic/prognostic roles of PTPN family members in digestive tract cancers. Cancer Cell Int. 2020, 20, 238. [CrossRef]

36. Hoffman, Y.; Bublik, D.R.; Pilpel, Y.; Oren, M. miR-661 downregulates both Mdm2 and Mdm4 to activate p53. Cell Death Differ. 2013, 21, 302-309. [CrossRef] [PubMed]

37. Li, Z.; Liu, Y.-H.; Diao, H.-Y.; Ma, J.; Yao, Y.-L. MiR-661 inhibits glioma cell proliferation, migration and invasion by targeting hTERT. Biochem. Biophys. Res. Commun. 2015, 468, 870-876. [CrossRef]

38. Vetter, G.; Saumet, A.; Moes, M.; Vallar, L.; Le Béchec, A.; Laurini, C.; Sabbah, M.; Arar, K.; Theillet, C.; Lecellier, C.-H.; et al miR-661 expression in SNAI1-induced epithelial to mesenchymal transition contributes to breast cancer cell invasion by targeting Nectin-1 and StarD10 messengers. Oncogene 2010, 29, 4436-4448. [CrossRef]

39. Zhu, T.; Yuan, J.; Wang, Y.; Gong, C.; Xie, Y.; Li, H. MiR-661 contributed to cell proliferation of human ovarian cancer cells by repressing INPP5J expression. Biomed. Pharmacother. 2015, 75, 123-128. [CrossRef] [PubMed]

40. Bui-Nguyen, T.M.; Pakala, S.B.; Sirigiri, D.R.; Martin, E.; Murad, F.; Kumar, R. Stimulation of Inducible Nitric Oxide by Hepatitis B Virus Transactivator Protein HBx Requires MTA1 Coregulator. J. Biol. Chem. 2010, 285, 6980-6986. [CrossRef]

41. Xu, R.; Yu, Y.; Zheng, S.; Zhao, X.; Dong, Q.; He, Z.; Liang, Y.; Lu, Q.; Fang, Y.; Gan, X.; et al. Overexpression of Shp2 tyrosine phosphatase is implicated in leukemogenesis in adult human leukemia. Blood 2005, 106, 3142-3149. [CrossRef]

42. Wang, Z.; Shen, D.; Parsons, D.W.; Bardelli, A.; Sager, J.; Szabo, S.; Ptak, J.; Silliman, N.; Peters, B.A.; van der Heijden, M.S.; et al. Mutational analysis of the tyrosine phosphatome in colorectal cancers. Science 2004, 304, 1164-1166. [CrossRef]

43. Révillion, F.; Puech, C.; Rabenoelina, F.; Chalbos, D.; Peyrat, J.-P.; Freiss, G. Expression of the putative tumor suppressor genePTPN13/PTPL1is an independent prognostic marker for overall survival in breast cancer. Int. J. Cancer 2008, 124, 638-643. [CrossRef] [PubMed] 
44. Bard-Chapeau, E.A.; Li, S.; Ding, J.; Zhang, S.S.; Zhu, H.H.; Princen, F.; Fang, D.D.; Han, T.; Bailly-Maitre, B.; Poli, V.; et al. Ptpn11/Shp2 Acts as a tumor suppressor in hepatocellular carcinogenesis. Cancer Cell 2011, 19, 629-639. [CrossRef]

45. You, M.; Yu, D.-H.; Feng, G.-S. Shp-2 Tyrosine phosphatase functions as a negative regulator of the interferon-stimulated Jak/STAT Pathway. Mol. Cell. Biol. 1999, 19, 2416-2424. [CrossRef]

46. Maeda, S.; Kamata, H.; Luo, J.-L.; Leffert, H.; Karin, M. IKK $\beta$ Couples Hepatocyte death to cytokine-driven compensatory proliferation that promotes chemical hepatocarcinogenesis. Cell 2005, 121, 977-990. [CrossRef]

47. Li, L.; Guo, J.; Chen, Y.; Chang, C.; Xu, C. Comprehensive CircRNA expression profile and selection of key CircRNAs during priming phase of rat liver regeneration. BMC Genom. 2017, 18, 80. [CrossRef]

48. Arsura, M.; Panta, G.R.; Bilyeu, J.D.; Cavin, L.G.; A Sovak, M.; Oliver, A.A.; Factor, V.; Heuchel, R.; Mercurio, F.; Thorgeirsson, S.S.; et al. Transient activation of NF-KB through a TAK1/IKK kinase pathway by TGF- $\beta 1$ inhibits AP- $1 /$ SMAD signaling and apoptosis: Implications in liver tumor formation. Oncogene 2003, 22, 412-425. [CrossRef]

49. Ren, X.; Wang, F.; Ji, B.; Gao, C. TLR7 agonist induced repression of hepatocellular carcinoma via the TLR7-IKK-NF-kB-IL6 signaling pathway. Oncol. Lett. 2016, 11, 2965-2970. [CrossRef] [PubMed]

50. Suzuki, H.; Zuo, Y.; Wang, J.; Zhang, M.Q.; Malhotra, A.; Mayeda, A. Characterization of RNase R-digested cellular RNA source that consists of lariat and circular RNAs from pre-mRNA splicing. Nucleic Acids Res. 2006, 34, e63. [CrossRef] [PubMed]

51. Memczak, S.; Papavasileiou, P.; Peters, O.; Rajewsky, N. Identification and characterization of circular RNAs As a new class of putative biomarkers in human blood. PLOS ONE 2015, 10, e0141214. [CrossRef] [PubMed]

52. Alhasan, A.A.; Izuogu, O.G.; Al-Balool, H.H.; Steyn, J.S.; Evans, A.; Colzani, M.; Ghevaert, C.; Mountford, J.C.; Marenah, L.; Elliott, D.; et al. Circular RNA enrichment in platelets is a signature of transcriptome degradation. Blood 2016, 127, e1-e11. [CrossRef] [PubMed]

53. Gaffo, E.; Boldrin, E.; Molin, A.D.; Bresolin, S.; Bonizzato, A.; Trentin, L.; Frasson, C.; Debatin, K.-M.; Meyer, L.H.; Kronnie, G.T.; et al. Circular RNA differential expression in blood cell populations and exploration of circRNA deregulation in pediatric acute lymphoblastic leukemia. Sci. Rep. 2019, 9, 14670. [CrossRef]

54. Lanford, R.E.; Hildebrandt-Eriksen, E.S.; Petri, A.; Persson, R.; Lindow, M.; Munk, M.E.; Kauppinen, S.; Ørum, H. Therapeutic Silencing of MicroRNA-122 in Primates with Chronic Hepatitis C Virus Infection. Science 2010, 327, 198-201. [CrossRef] [PubMed]

55. Krützfeldt, J.; Rajewsky, N.; Braich, R.; Rajeev, K.G.; Tuschl, T.; Manoharan, M.; Stoffel, M. Silencing of microRNAs in vivo with 'antagomirs'. Nature 2005, 438, 685-689. [CrossRef]

56. Stebbing, J.; Lit, L.; Zhang, H.; Darrington, R.; Melaiu, O.; Rudraraju, B.; Giamas, G. The regulatory roles of phosphatases in cancer. Oncogene 2013, 33, 939-953. [CrossRef] [PubMed] 